\title{
Towards the participant observation of emotions in software development teams
}

\author{
Michal R. Wrobel \\ Faculty of Electronics, Telecommunications and Informatics, \\ Gdansk University of Technology, Poland \\ Email: wrobel@eti.pg.gda.pl
}

\begin{abstract}
Emotions, moods and temperament influence our behaviour in every aspect of life. Until now plenty of research has been conducted and many theories have been proposed to explain the role of emotions within the working environment. However, in the field of software engineering, interest in the role of human factors in the process of software development is relatively new. In the paper the research design process that has been proposed details a novel approach using the method of participant observation in order to investigate the role of emotions in IT projects. The participant observation protocol presented was developed in an iterative manner, where successive phases were validated in two preliminary studies.
\end{abstract}

\section{INTRODUCTION}

C OMPUTER programs are used in almost every aspect of our lives. At the same time, a considerable part of IT projects fail. Budgets or schedules are exceeded, applications are low quality. The Standish Group estimated in their "2015 CHAOS Report" that $19 \%$ of the IT projects failed, and only $29 \%$ were entirely successful [1]. Available techniques and methods of software engineering solve the problems only partially. One of the directions of research that can improve the success factors of an IT project is the analysis of human factors in the process of software development. Emotions, moods and temperament influence our behaviour in every aspect of life. Such impact is sometimes more, sometimes less significant. Modern research of emotions in the workplace were initiated in 1983 by Hochschild's book "The Managed Heart". Since then, numerous research has been conducted and many theories have been proposed so as to explain the role of the emotions in work [2].

However, in the field of software engineering interest in the role of human factors in the process of software development is relatively new. Software development is considered as one of the most complicated tasks performed by humans, not only because of the technical complexity, but also due to human factors [3]. Nowadays, software development require a high level of cooperation between a number of individuals with different personalities, which may raise interpersonal conflicts. While the technical and management issues have been covered in numerous studies, the awareness of importance of human aspects is still minimal.

This low awareness of the role of emotions in the software engineering is partly due to the small number of research in this field. In Section II studies on emotions in the software development process are presented. In most studies quantitative methods were used, however, these methods allow confirmation of the hypothesis, or more accurate data on the phenomenon to be obtained, which, at least in part, is understandable. Whereas knowledge about the impact and the role of emotions in the software development is still negligible. To fill this gap, I propose to conduct experiments using the method of participant observation, taken from ethnography science. In Section III the experiment design is proposed. To confirm the validity of the assumptions and design, preliminary studies were conducted. Information about its execution and results are presented in Section IV.

With the current state of knowledge concerning the role of emotions in the work of IT professionals, it is necessary to carry out further detailed observations. The application of the proposed and validated participant observation study should allow a better insight on the impact of emotions in the software development process.

\section{STUDIES ON EMOTIONS OF SOFTWARE DEVELOPERS}

Credible studies on the role of emotions in the software development process started only in the XXI century. However, so far they have been conducted mainly without immersion in the work of software developers. Graziotin et al. compared self-assessed affective states with self-assessed productivity of the programmers. Their study revealed correlation between productivity and both valence and dominance [4]. A similar study was conducted by Khan et al. In the experiment, participants watched short video clips that were meant to affect their mood. Before conducting programming and debugging tasks, they assessed their emotional state. Results showed weak correlation between arousal and productivity [5].

Recently a few studies on emotions of software developers were conducted using sentiment analysis technique. This is a completely passive method of gathering information regarding the attitude of the authors based on the analysis of their texts. Garcia et al. performed such study on the basis of artifacts generated by the Gentoo Community, such as mailing lists and bug tracker. Results of their experiment showed a correlation between developers' emotional states and activity [6]. A similar experiment, performed by Muriga et al. showed that only a small subset of emotions can be detected based on data mining techniques [7]. 
The common element among all this research is the lack of direct contact with respondents during data collection. Collecting such confidential and ambiguous data, in the form of information concerning emotions, require gaining the trust of the respondent. Another issue is the problem with the naming of emotions. People ambiguously interpret names of emotions, which leads to biased data.

A novel approach to recognizing the emotions of software developers was proposed by Muller et al. In two experiments, they used biofeedback devices to gather EEG, EDA, fMRI and eye-tracker signals of developers during their work [8]. Biometric signals provide objective information about reactions of the human body to emotional stimuli. Nevertheless, current knowledge does not allow unambiguous assignment of emotional states on the basis of this data [9].

Another approach was proposed by Graziotin et al. During their study, a researcher constantly supervised the experiment and respondents were observed while programming. Before and after the development task, a face to face interview was performed [10]. Such approach allows more accurate observation of the behaviour of developers, and thus better understanding of the impact of emotions upon their work.

\section{THE RESEARCH DESIGN}

To gather significant insights in the role of emotions within the software development process, I propose to use a participant observation method, known from ethnography science. Review of the emotion management literature performed by Fisher et al. showed usefulness of participant observation and interviews in examining emotions in the workplace [2].

Observation is a research method that allows detail qualitative information to be gathered. It is defined as systematic description of the events and behaviours in environment [11]. A particular type of this method is participant observation, where the researcher takes an active part in daily events and activities of the group and interacts with its members [12]. Seaman et al. confirmed that participant observation allows to obtain comprehensive data about software development process [13].

For the purpose of the study, in order to obtain information about emotions and moods of the developers and the impact of these factors on their work, participant as an observer method was chosen. It means that the observer is a member of the group and she or he takes full part in its activities. Other members of the group are aware of being the subject of the experiment. The observer during work can collect data about the colleagues, but also observe her or his own behaviour and the factors that influence them. This permits deeper, though subjective, behavioural analysis. In order to eliminate subjective factors it is planned to make a number of observations by independent researchers.

Research is supposed to be fully overt. Employers of the researchers should provide formal agreement to place studies in their facilities. Also, team members will be informed about studies and will have to give their approval. All data will be anonymised to prevent identification of individual employees. The employer will not have access to the collected data, and will only receive a final report containing summary information.

Information will be collected in a continuous manner. The observer will separately take notes about emotional states, as well as events occurred throughout the work day.

\section{A. Preliminary studies}

The participant observation study was designed in an iterative manner. Initial experiment assumptions about the observation were verified during two subsequent preliminary studies. Such approach allowed the identification of the design flaws and to propose a better, more mature research design.

There were two participant observations conducted. Both were performed by software developers with bachelors' degrees in Computer Science (polish engineer's degree). They were students of second level studies and they were working part-time (20 hours per week) in two different IT companies as software developers.

The first observation took place in May 2015 and lasted for three weeks. During this time the observer made 121 notes about himself, and his colleagues made 79 notes about their own emotional states.

The second observer worked with 3 other software developers. During four weeks in June 2015, he made 162 observations about his own emotions and 78 notes about emotions of his colleagues. Furthermore, his co-workers made 81 notes about their own emotions.

\section{B. Notes templates}

For the purpose of the observation initially two template notes were prepared, named as the Sheet $S$ and the Sheet A.

Information on the emotions of the observer will be collected continuously, i.e. during work, she or he must pay attention to emotional states and well-being, as well as to analyse their impact on the productivity. After every hour the observer makes notes about his emotions and productivity using Sheet S. Additionally, at the end of the working day, each co-worker is asked to describe her or his emotional state and productivity during the day, their insights are then documented on the Sheet A. Each observation is documented on the sheet by filling in four fields: emotional state, fatigue, productivity and additional notes.

For purposes of denoting emotional states the Russell circumplex model of affect was chosen [14]. According to this model, emotions are described with two continuous dimensions of valence and arousal. The valence (pleasure) dimension differentiates positive from negative emotions, and as it is continuous, both directions might be graded. Values close to zero correspond to neutral emotional states. The dimension of arousal (activation) allows the differentiation of active and passive emotional states. The value of zero means relaxed or calm, while four indicates excited or stimulated [15].

In the fatigue field it is possible to indicate whether it was present or not. Information regarding the productivity is denoted using a grade 5 scale, where 0 represents no 
Participant observation of software developers

\begin{tabular}{|c|c|c|c|c|c|c|c|c|c|c|}
\hline \multirow{2}{*}{\begin{tabular}{|c|} 
Observer code: \\
Work hour \\
\end{tabular}} & \multicolumn{6}{|c|}{ Date: } & \multicolumn{2}{|c|}{ Experiment day: } & \multirow{2}{*}{$\begin{array}{r}\text { Work hours: } \\
\text { Notes } \\
\end{array}$} & \multirow[t]{2}{*}{$\mathbf{S}$} \\
\hline & & Emo & ona & sta & & & Fatigue & Productivity & & \\
\hline 1 & $\begin{array}{l}\text { Valence } \\
\text { Arousal: }\end{array}$ & $\begin{array}{r}-2 \\
0\end{array}$ & $\begin{array}{r}-1 \\
1\end{array}$ & $\begin{array}{l}0 \\
2\end{array}$ & $\begin{array}{l}1 \\
3\end{array}$ & $\begin{array}{l}2 \\
4\end{array}$ & yes / no & $\begin{array}{lllll}0 & 1 & 2 & 3 & 4\end{array}$ & & \\
\hline 2 & $\begin{array}{l}\text { Valence } \\
\text { Arousal: }\end{array}$ & $\begin{array}{r}-2 \\
0\end{array}$ & $\begin{array}{r}-1 \\
1\end{array}$ & $\begin{array}{l}0 \\
2\end{array}$ & $\begin{array}{l}1 \\
3\end{array}$ & $\begin{array}{l}2 \\
4\end{array}$ & yes / no & $\begin{array}{lllll}0 & 1 & 2 & 3 & 4\end{array}$ & & \\
\hline 3 & $\begin{array}{l}\text { Valence } \\
\text { Arousal: }\end{array}$ & $\begin{array}{r}-2 \\
0\end{array}$ & $\begin{array}{r}-1 \\
1\end{array}$ & $\begin{array}{l}0 \\
2\end{array}$ & $\begin{array}{l}1 \\
3\end{array}$ & $\begin{array}{l}2 \\
4\end{array}$ & yes / no & $\begin{array}{lllll}0 & 1 & 2 & 3 & 4\end{array}$ & & \\
\hline 4 & $\begin{array}{l}\text { Valence } \\
\text { Arousal: }\end{array}$ & $\begin{array}{r}-2 \\
0\end{array}$ & $\begin{array}{r}-1 \\
1\end{array}$ & $\begin{array}{l}0 \\
2\end{array}$ & $\begin{array}{l}1 \\
3\end{array}$ & $\begin{array}{l}2 \\
4\end{array}$ & yes / no & $\begin{array}{lllll}0 & 1 & 2 & 3 & 4\end{array}$ & & \\
\hline 5 & $\begin{array}{l}\text { Valence } \\
\text { Arousal: }\end{array}$ & $\begin{array}{r}-2 \\
0\end{array}$ & $\begin{array}{r}-1 \\
1\end{array}$ & $\begin{array}{l}0 \\
2\end{array}$ & $\begin{array}{l}1 \\
3\end{array}$ & $\begin{array}{l}2 \\
4\end{array}$ & yes / no & $\begin{array}{lllll}0 & 1 & 2 & 3 & 4\end{array}$ & & \\
\hline 6 & $\begin{array}{l}\text { Valence } \\
\text { Arousal: }\end{array}$ & $\begin{array}{r}-2 \\
0\end{array}$ & $\begin{array}{r}-1 \\
1\end{array}$ & $\begin{array}{l}0 \\
2\end{array}$ & $\begin{array}{l}1 \\
3\end{array}$ & $\begin{array}{l}2 \\
4\end{array}$ & yes / no & $\begin{array}{lllll}0 & 1 & 2 & 3 & 4\end{array}$ & & \\
\hline 7 & $\begin{array}{l}\text { Valence } \\
\text { Arousal: }\end{array}$ & $\begin{array}{r}-2 \\
0\end{array}$ & $\begin{array}{r}-1 \\
1\end{array}$ & $\begin{array}{l}0 \\
2\end{array}$ & $\begin{array}{l}1 \\
3\end{array}$ & $\begin{array}{l}2 \\
4\end{array}$ & yes / no & $\begin{array}{lllll}0 & 1 & 2 & 3 & 4\end{array}$ & & \\
\hline 8 & $\begin{array}{l}\text { Valence } \\
\text { Arousal: }\end{array}$ & $\begin{array}{r}-2 \\
0\end{array}$ & $\begin{array}{r}-1 \\
1\end{array}$ & $\begin{array}{l}0 \\
2\end{array}$ & $\begin{array}{l}1 \\
3\end{array}$ & $\begin{array}{l}2 \\
4\end{array}$ & yes / no & $\begin{array}{lllll}0 & 1 & 2 & 3 & 4\end{array}$ & & \\
\hline 9 & $\begin{array}{l}\text { Valence } \\
\text { Arousal: }\end{array}$ & $\begin{array}{r}-2 \\
0\end{array}$ & $\begin{array}{r}-1 \\
1\end{array}$ & $\begin{array}{l}0 \\
2\end{array}$ & $\begin{array}{l}1 \\
3\end{array}$ & $\begin{array}{l}2 \\
4\end{array}$ & yes / no & $\begin{array}{lllll}0 & 1 & 2 & 3 & 4\end{array}$ & & \\
\hline General notes: & & & & & & & & & & \\
\hline
\end{tabular}

Fig. 1. Observer notes template - Sheet $S$

productivity, and 4 the highest productivity. Furthermore, for each observation as to the events influencing the emotional states and productivity should be described within the notes field.

After the first participant observations, lack of regularity and credibility in fulfilling sheets by co-workers was noticed. Therefore, an additional template, marked as Sheet O, was prepared. It is meant for taking notes by the observer about emotions of colleagues and their productivity. During his work, observer should non-invasively watch her or his co-workers. Particular attention should be paid to the events affecting their emotions.

Sheet S (Fig. 1) contains 9 rows of the fields described above, each row for every hour of the working day. The number of rows in the Sheet A, corresponds to the number of co-workers observed. Sheet O contains just one row. Sheets also includes additional information, such as observer code, date of observation and working hours. After each working day $n+2$ sheets should be collected, where $n$ is the number of co-workers.

\section{RESULTS OF PRELIMINARY STUDY}

In the context of designing the participant observation research, the most important outcome of the preliminary study refers to the issue of observing co-workers. The first observation revealed, and the second confirmed, that co-workers are not willing to systematically fill observation sheets, even if it is required only once a day. Only $25 \%$ of the notes were taken on time - at the end of the working day, or at the beginning of the next one, the remaining were delivered with delay.

Therefore, during the second execution, the observer was asked to take notes about her or his colleagues. These notes
TABLE I

NUMBER OF REPORTED HIGH AND LOW PRODUCTIVITY DEPENDING ON THE ARousal AND THE VAlence

\begin{tabular}{|l|r|r|r|r|r|}
\hline \multirow{2}{*}{ Productivity } & \multicolumn{5}{|c|}{ Arousal } \\
\cline { 2 - 6 } & 0 & 1 & 2 & 3 & 4 \\
\hline \hline Low & 31 & 42 & 63 & 42 & 1 \\
\hline High & 9 & 16 & 123 & 51 & 2 \\
\hline \hline Total & 59 & 98 & 285 & 106 & 3 \\
\hline \hline \multirow{2}{*}{ Productivity } & \multicolumn{5}{|c|}{ Valence } \\
\cline { 2 - 6 } & -2 & -1 & 0 & 1 & 2 \\
\hline \hline Low & 5 & 31 & 61 & 54 & 28 \\
\hline High & 0 & 11 & 37 & 121 & 40 \\
\hline \hline Total & 6 & 67 & 154 & 250 & 82 \\
\hline
\end{tabular}

have been compared with the notes taken by the co-workers observed. The analysis showed that the external evaluation agreed only on not more than $25 \%$ of notes with the selfassessment. While the assessment of valence and arousal were sometimes under, and sometimes over-estimated, in the case of productivity, co-workers always have reported greater diligence than suggested by the external evaluation.

These results indicate the necessity to involve objective methods for identifying emotions and productivity evaluation. Without proper tools support [16], observation of emotional states and productivity of co-workers is useless. Therefore, in further studies only self-assessment of a trained observer will be conducted.

Based on the collected data, analysis of the impact of emotional states on productivity has been conducted. Fig. 2 and Table I show the number of reported high and low 


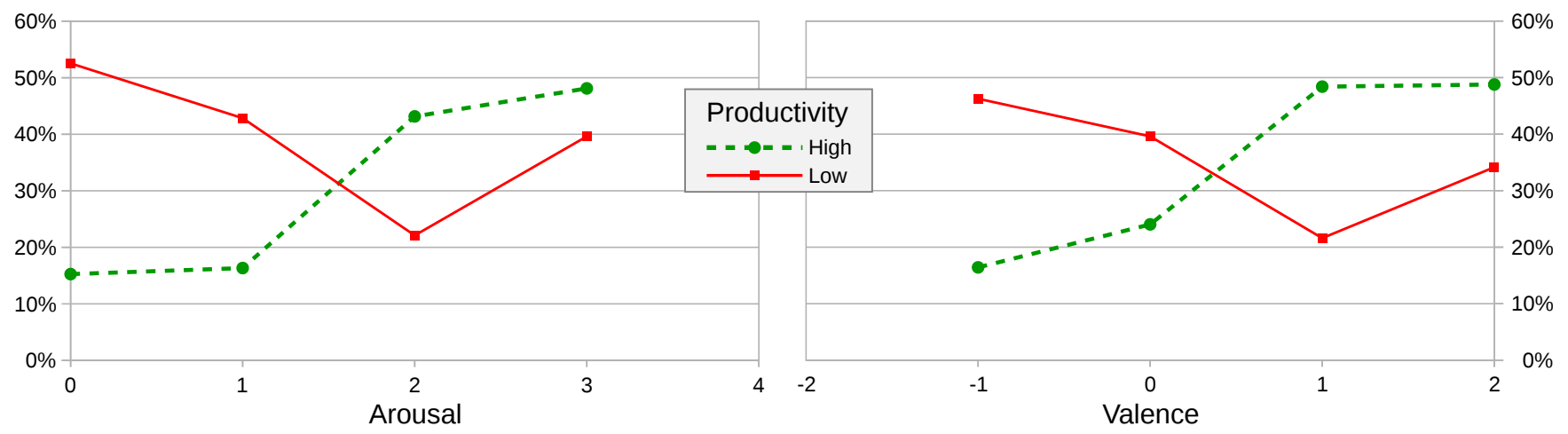

Fig. 2. Percentage of high and low productivity of software developers, depending on their arousal and valence

productivity periods depending on the arousal and valence. Due to the small number of observations, results with the highest arousal and the lowest valence were removed from the chart.

Low productivity is least likely to occur at an average arousal and higher value of valence. Correlation between high productivity and both arousal and valence seems to be more linear. High value of productivity was reported more frequently along with high arousal and high valence. Considering the results above, it appears that the optimum in terms of productivity of software developers, is medium arousal and high valence.

\section{CONCLUSION}

Preliminary studies have proved that the proposed research design may bring new and useful information on the role of emotions in the software development process. The use of qualitative research methods may allow for a better understanding the role of emotions in productivity of IT professionals.

Preliminary studies have also discredited the legitimacy of both external and self-assessment of co-workers. Therefore, it is proposed that observers make out notes only on their own emotional states and productivity. Observation of other team members will be possible only after the development of a reliable and non-intrusive methods of emotion recognition and productivity evaluation.

In addition, the results of the two preliminary participant observation studies showed the correlation between high productivity and both arousal and valence. Optimal, in the case of productivity, emotional states include, among others, joy, amusement, surprise and anxiety.

Understanding the role of emotions in the software engineering may lead to the development of new affect-aware extensions to both traditional and modern software development management methodologies.

\section{ACKNOWLEDGMENT}

I thank my students R. Lewandowski and J. Falenczyk for conducting the preliminary participant observations described in the paper.

\section{REFERENCES}

[1] The Standish Group, "2015 Chaos Report,” Tech. Rep., 2015.

[2] C. D. Fisher and N. M. Ashkanasy, "The emerging role of emotions in work life: an introduction," Journal of Organizational Behavior, vol. 21, pp. 123-129, 2000. doi: 10.1002/(sici)10991379(200003)21:2<123::aid-job33>3.0.co;2-8

[3] F. L. Capretz, "Bringing the human factor to software engineering," IEEE Software, vol. 31, no. 2, pp. 104-104, 2014. doi: 10.1109/MS.2014.30

[4] D. Graziotin, X. Wang, and P. Abrahamsson, "Are Happy Developers More Productive?" in Proceedings of the 14th International Conference PROFES, 2013, pp. 50-64. doi: 10.1007/978-3-642-39259-7

[5] I. A. Khan, "Mood Independent Programming," in Proceedings of the 14th European conference on Cognitive ergonomics: invent! explore!, 2007, pp. 269-272. doi: 10.1145/1362550.1362606

[6] D. Garcia, M. S. Zanetti, and F. Schweitzer, "The role of emotions in contributors activity: a case study on the gentoo community," in Cloud and Green Computing (CGC), 2013 Third International Conference on. IEEE, 2013, pp. 410-417. doi: 10.1109/CGC.2013.71

[7] A. Murgia, P. Tourani, B. Adams, and M. Ortu, "Do developers feel emotions? an exploratory analysis of emotions in software artifacts," Conference on Mining Software, pp. 262-271, 2014. doi: $10.1145 / 2597073.2597086$

[8] T. Fritz and S. C. Müller, "Stuck and Frustrated or In Flow and Happy: Sensing Developers Emotions and Progress," in 37th International Conference on Software Engineering (ICSE 2015), 2015. doi: 10.1109/icse.2015.334

[9] A. Landowska, "Emotion monitor-concept, construction and lessons learned," in Federated Conference on Computer Science and Information Systems (FedCSIS). IEEE, 2015, pp. 75-80. doi: 10.15439/2015F264

[10] D. Graziotin, X. Wang, and P. Abrahamsson, "Do feelings matter? On the correlation of affects and the self-assessed productivity in software engineering," Journal of Software: Evolution and Process, pp. 1-21, 2014. doi: $10.1002 / \mathrm{smr} .1673$

[11] C. Marshall, C. B. Rossman, and G. B. Rossman, Designing qualitative research. Sage publications, 2010. ISBN 141297044X

[12] K. M. DeWalt, B. DeWalt R., and C. B. Wayland, Participant $O b-$ servation: A Guide for Fieldworkers. AltaMira Press, 2010. ISBN 0759100446

[13] C. B. Seaman, "Qualitative methods in empirical studies of software engineering," IEEE Transactions on Software Engineering, vol. 25, pp. 557-572, 1999. doi: 10.1109/32.799955

[14] J. A. Russell, "A circumplex model of affect," Journal of personality and social psychology, vol. 39, no. 6, p. 1161, 1980. doi: 10.1037/h0077714

[15] A. Kolakowska, A. Landowska, M. Szwoch, W. Szwoch, and M. R. Wrobel, "Modeling emotions for affect-aware applications," in Information Systems Development and Applications. Faculty of Management, University of Gdask, Poland, 2015.

[16] A. Kołakowska, A. Landowska, M. Szwoch, W. Szwoch, and M. R. Wróbel, "Emotion recognition and its applications," Human-Computer Systems Interaction: Backgrounds and Applications 3, pp. 51-62, 2014. doi: 10.1007/978-3-319-08491-6_5 